Vol. 1, No. 1, 2019

https://doi.org/10.23939/cds2019.01.034

O. Belej

Lviv Polytechnic National University

\title{
THE MAIN CLUSTER NODE FORMATION IN WIRELESS SENSORY NETWORKS
}

(C) Belej O., 2019

In wireless sensor networks, the clustering method is often used to transmit information, which is one of the most energy efficient approaches. Since the master cluster node interacts with other nodes in the network, a node with a high residual energy is selected to perform its functions. The technology of selecting the main node based on fuzzy logic, which involves the use of a number of input parameters, the effect of which is demonstrated in the article, is proposed.

Key words: wireless sensory network, cluster, algorithm, main cluster node, nonsense logic.

\section{Problem statement}

One of the areas of the Internet of Things development (IoT) is the construction of pervasive sensor networks, which are based on self-organizing wireless networks [1].

Wireless All-Push Sensor Networks (WASN) are self-organizing networks that consist of a multitude of wireless sensor nodes distributed in space and designed for monitoring and controlling the characteristics of the environment or objects located therein [2]. The space that is covered by the sensor network is called the touch field. Wireless sensor nodes are miniature devices with limited resources: battery charge, memory capacity, computing capabilities. However, combining a large number of these elements into the network due to the effect of Roya intelligence [3] provides an opportunity to get a real picture of the events occurring and processes within this sensory field.

Since sensory nodes have limited energy, clustering is the result of its energy efficiency for use in the WASN before the respectful approach. Clustering is the process of organizing nodes into groups called clusters. Clustering allows you to save energy, as data transfer is limited to several nodes, which increases the life of the sensor network [4]. Formation of clusters in a dynamic environment is one of the main problems of hierarchical routing as it affects energy consumption in WASN.

The cluster organization is efficient and scalable for the functioning of the WASN, but only if the rational choice of the main node in the cluster network is a specific time point [5]. In addition, speaking of the functioning of the WASN, it should be borne in mind that the network may be formed by some set of nodes, each of which is within the reach of at least one node of this set, and each node has the ability to send the destination node data, which may be a gateway or any other network node [6].

A wide variety of implementations and application areas of wireless systems, self-organizing networks leads to the need for analysis of their properties and determination of methods for evaluating the main parameters.

The purpose of this work is to identify the basic parameters of the functioning of the wireless sensor network and their dependence on the algorithm for selecting the main node of the sensor network at different densities of sensor nodes on the plane.

\section{Analysis of recent research and publications}

When using clustering, each cluster selects the main cluster nodes (MCN), which serve to collect data from cluster nodes and transmit them to the base station. How the MCN can be selected node with any level of residual energy, including the minimum. However, a large number of main nodes with low energy 
can lead to network failure. That is why the characteristics of the MCN determine the performance of the cluster and of the whole WASN as a whole, and the choice of the main cluster node plays an essential role in the functioning of the sensor networks [7].

One of the most well-known algorithms that provide the operation of sensor networks and the selection of main nodes is the Low Energy Adaptive Cluster Hierarchy (LEACH) algorithm. The LEACH algorithm involves the probabilistic choice of the sensor node for the role of the main at the beginning of the functioning of the sensor network, and subsequently - rotation based on the energy characteristics of the sensor nodes. This approach extends the duration of the operation of sensor nodes and the network as a whole, but does not allow solving the problem of providing better coverage over a sufficiently long period of time [8].

Many researchers proposed schemes for selecting MCN based on various factors such as residual energy nodes, distance from base station to node, distance between MCN and cluster member, number of adjacent nodes, proximity to neighboring nodes [9]. However, in early works, the factor of energy consumption was not considered, how many times the nodes communicate with each other.

The BSS structure, consisting of a base station and two clusters, in conjunction with their MCN and members of the cluster, is shown in Fig. 1.

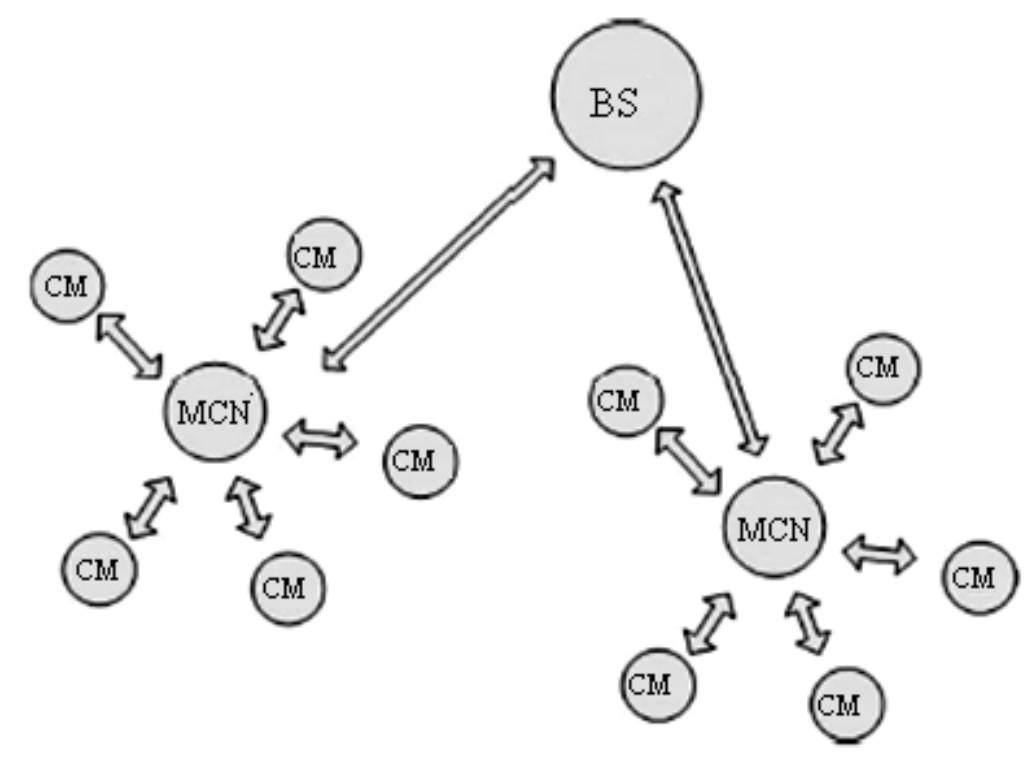

Fig. 1. The structure of the wireless sensor network: $B S$ - base station; $C M$ - a cluster member

We show the functioning of the MCN with hierarchical clustering. Let's take two nodes of the same cluster. The node with the highest level of energy, which carries out frequent interaction with other nodes, is denoted as the node "A". The node " $\mathrm{B}$ " is a node with a relatively lower level of energy, it is much less common to exchange data with other nodes. The node "A" will be selected as the MCN due to its higher energy level, while the node "B" will be simply a member of the MCN cluster. Under this scenario, the energy of the node " $\mathrm{A}$ " is spent faster because of its frequent interaction in other nodes, while the energy costs of the node "B" will be negligible compared with the energy costs of the node "A" due to its rare data exchanges with another network nodes [10].

To eliminate this disadvantage, we propose an algorithm for choosing the MCN based on fuzzy logic. The choice of the MCN is based on the distance between the node and the base station, the amount of residual energy and the number of neighboring nodes. 


\section{Formulating the whole of article}

Consider the model proposed by Jin Shyan Lee [11], which does not take into account the need for energy nodes, which occurs in downtime or sleep mode. In this model it is assumed that each one amplifies a data bit based on a schedule that has the energy and amount of energy for data transmission, which is given as:

$$
E_{T x}=\left\{\begin{array}{l}
l \cdot E+l \varepsilon_{e s} \cdot d^{2}, d<d_{0}, \\
l \cdot E+l \varepsilon_{a e c} \cdot d^{2}, d<d_{0},
\end{array}\right.
$$

where $\varepsilon_{e s}$ is the factor affecting the energy consumption of the free space model; $\varepsilon_{\text {aec }}$ is a factor affecting energy consumption for models of multipath propagation of waves; $\mathrm{d} 0$ is the threshold value.

The boundary value of $\mathrm{d} 0$ can be given as follows:

$$
d_{0}=\sqrt{\frac{\varepsilon_{e s}}{\varepsilon_{a e c}}} .
$$

Depending on the timetable used either the free space model or the reusable model.

The energy required for each node to receive data from $E_{p r}$ is defined as:

$$
E_{p r}=l \cdot E \text {. }
$$

This model calculates the energy intensity of the transmission of the $E_{p l}$ and the reception of the $E_{p r}$ node, not taking into account the role of the node in the cluster, it is not taken into account, it is the main cluster vole or member of the cluster. The execution of role nodes in the main cluster node or cluster member varies depending on their tasks. Depending on how many times the WASN node interacts with other nodes in the network, which indicates the corresponding role, and, accordingly, energy consumption varies depending on whether it is a member of the cluster or the main class. Next, the energy consumption of the MCN of EGCU and its members of the EHC can be calculated independently of the second by modifying the expressed (1) and (2), taking into account the repetition frequencies of the holy sensor node. EGCU and EHC are calculated as follows:

$$
\begin{aligned}
& E_{B C M}=E_{p r_{B S}}+\left(E_{p r_{C M}}+E_{p l_{C M}} \cdot m\right)+E_{A}+E_{p l_{B S}}, \\
& E_{C M}=E_{p r_{B C M}}+E_{p l_{B C M}},
\end{aligned}
$$

where $E_{p r_{B S}}$ - energy required by the MCN when receiving a message from the base station; $E_{p l_{B S}}$ - energy required by the $\mathrm{MCN}$ for the transmission of aggressive data to the base station; $E_{p_{C M}}$ - energy required by the MCN when receiving data from members of the cluster; $E_{p l_{C M}}$ - the energy required by the MCN when communicating a member of the cluster; $E_{A}$ - energy required by the MCN for aggregation of data; $\mathrm{m}$ - the number of nodes in the class $E_{p r_{B C M}}$ - the energy required when turning on the message from the MCN; $E_{p l_{B C M}}$ - energy spent by the node for data transfer from the node to the HCU.

The results indicate that direct use of coherent merging of capacities of close nodes may not be possible. Make effective use of the proposed method of collective transfer of information using adaptive phase-setting algorithms. However, many tasks related to the use of sensor networks require the use of the cheapest wireless nodes having the most feasible device, including the implementation of complex adaptive algorithms created on the optimum basis of phase shifts to ensure maximum level of occurrence. Calculate the simplest algorithm that can be implemented in cheap sensors. As already mentioned above, it is assumed that the relationship between clusters should be bi-directional. Upon completion of the message cluster, the cluster's central node awaits confirmation of the acceptance of the message data by other 
clusters. The information confirming the correct reception can be received directly by the central node or any other node in the cluster, initiator of data transmission, as well as transmission to the central node. In Fig. 2 graphs are presented, but using random selection of phase shifts. In this case, in each case, the maximum number of random phases of the equation of four will be set. As can be seen, even such a random phase shift approach allows a qualitative improvement of the network connection by using the method of collective transfer of information.

Fig. 2. The dependence of the network's connectivity without clustering (dotted-1,3) and clusterization (the burst line is 2, 4) from the parameter $d$ for the total number of nodes $N=1700$ (lines 3, 4) and $N=2000($ lines 1,2$)$

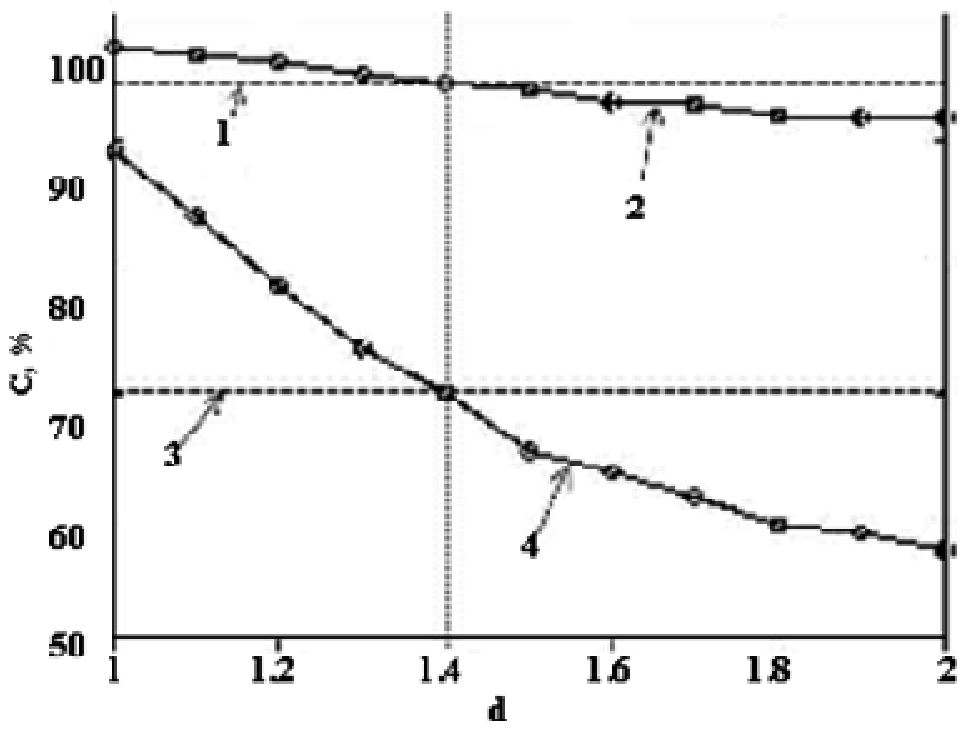

Fig. 3. Energy degradation of the sensor network without the use of the method of collective information transfer (solid line) and using the method of collective transfer of information, which includes after 21 cycle of the network (dotted line)

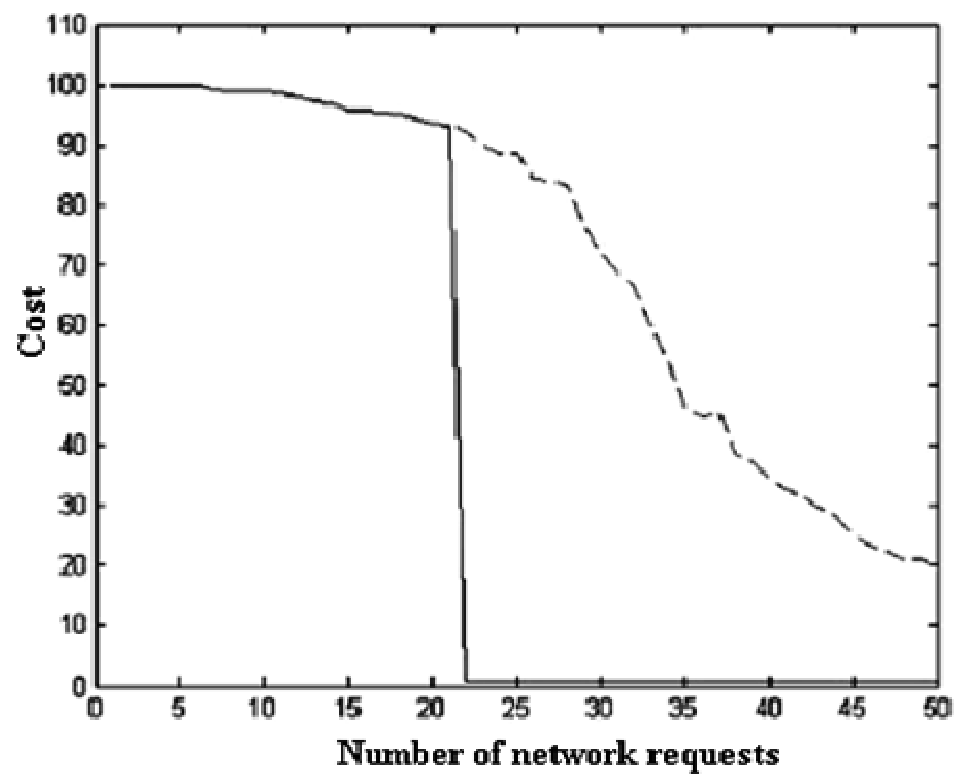

In the typical mode of operation, allocate nodes in the sensor network to transmit information to the base station, which provides data storage and access to it through other networks or the Internet. All information flows refer to the base station, therefore the maximum energy load lies on the node located in close proximity to the base station. As a result of energy degradation, these nodes are coming out of time by separating the base station from all other stationary units whose energy resources are not yet available. In Fig. 3 graphs illustrated, energy degradation of the sensor network - dependence of the connection on the number of network attempts. In this case, the relative number of nodes is understood, information from which can be delivered to the base station. In the experiment, it was assumed that the data is transmitted to 
the base station periodically, that is, the base station, which broadens the broadband request, after which everything begins to transmit its information. Each such transfer of information is called the description of the network. When clustering information is generated energy-false costs for the previous exchange of data in the cluster and a clasical view of this information. The energy expended on receiving and transmitting one message from another goal is determined by the following formula:

$$
W_{\text {relay }}=W_{r x}+W_{t x} \text {, }
$$

where $W_{r x}$ - energy consumption in the receiver, $W_{t x}$ - power consumption in the transmitter. Energy consumed for change and transmission of test parameters:

$$
W_{\text {sense }}=W_{s}+W_{t x} \text {, }
$$

where $W_{s}$ is the energy consumed in the sensor. When simulating energy costs, $W_{\text {sense }}=W_{\text {relay }}=0.5 \mathrm{~mJ}$. As a result of the computer experiment (Fig. 3), the use of the method of collective information transfer was obtained, which allows for effective time of functioning of the sensory network approximately one and a half times.

\section{Presenting main material}

In the general case, the energy of the MCN and members of the WASN cluster is spent in the process of sensing, processing data and mutual exchanges of information. Thus, when the value of the energy level of the MCN becomes less than the threshold, this MCN ceases to be the main one, which leads to re-election of the Central Committee. In such cases, the node often interacts with other nodes in the cluster, there is a likelihood of becoming a MCN considering its high level of residual energy at the current time. However, this is a significant disadvantage: since the energy of the node involved in the constant exchange of data with neighboring nodes will be rapidly depleted compared with the nodes exchanging data much less often, this will lead to frequent re-choices of the MCN. On the other hand, if the energy consumption of the MCN and members of the cluster can be predicted on the basis of their previous communication sessions, then the interval of re-election of the Central Committee can be increased in this way. In order to solve this problem, the method of selecting the MCN of WASN is based on fuzzy logic. In Fig. 4 presents a model of a fuzzy-controlled system for selecting a MCN. The input parameters are the residual energy of the nodes (RE), the distribution density of the neighboring nodes in the cluster (ND) and the centrality of the node (NC), and the output parameter is the probability of choosing the CHS.

The linguistic variables RE and ND are "Low", "Average", "High", and the NC variable is "Near", "Medium", "High". In Fig. 5 the functions of the membership of the input parameters of the system are presented. Based on knowledge of linguistic change, 27 rules of fuzzy logic are used to decide on the probability of choosing a node as a MCN .

The closer the value of the output parameter will be to one, the higher the probability of the node becoming the MCN in the WASN. The proposed fuzzy rule system takes a decision based on three basic parameters in accordance with the predefined rule base given.

In Fig. 6-8 presented graphic surfaces of inputs and outputs is modeled by a fuzzy control system.

According to the data in Fig. 6, for the node the probability of being selected as the MCN will be high with a high level of residual energy and high density distribution of nodes in the cluster. At a high level of residual energy and the close location of the node to the center of the cluster, the probability of becoming a MCN in the node is also high, as shown in Fig. 7. This situation is desirable, since the more central the MCN position will be, the smaller will be the cost of energy for the exchange of data with the members of the WASN cluster. In Fig. 8 shows that with the increase in the distribution density of nodes in the cluster and the close centralization of the node, the probability of the node being selected as the MCN increases. 


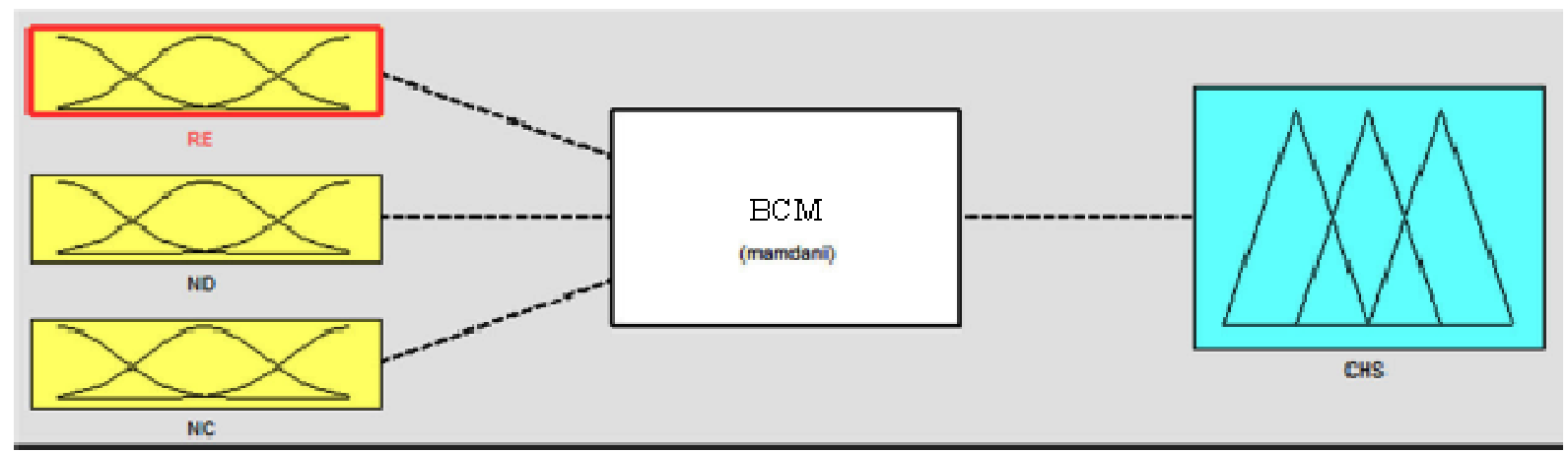

Fig. 4. Model of an unclearly managed system for the choice of MCN

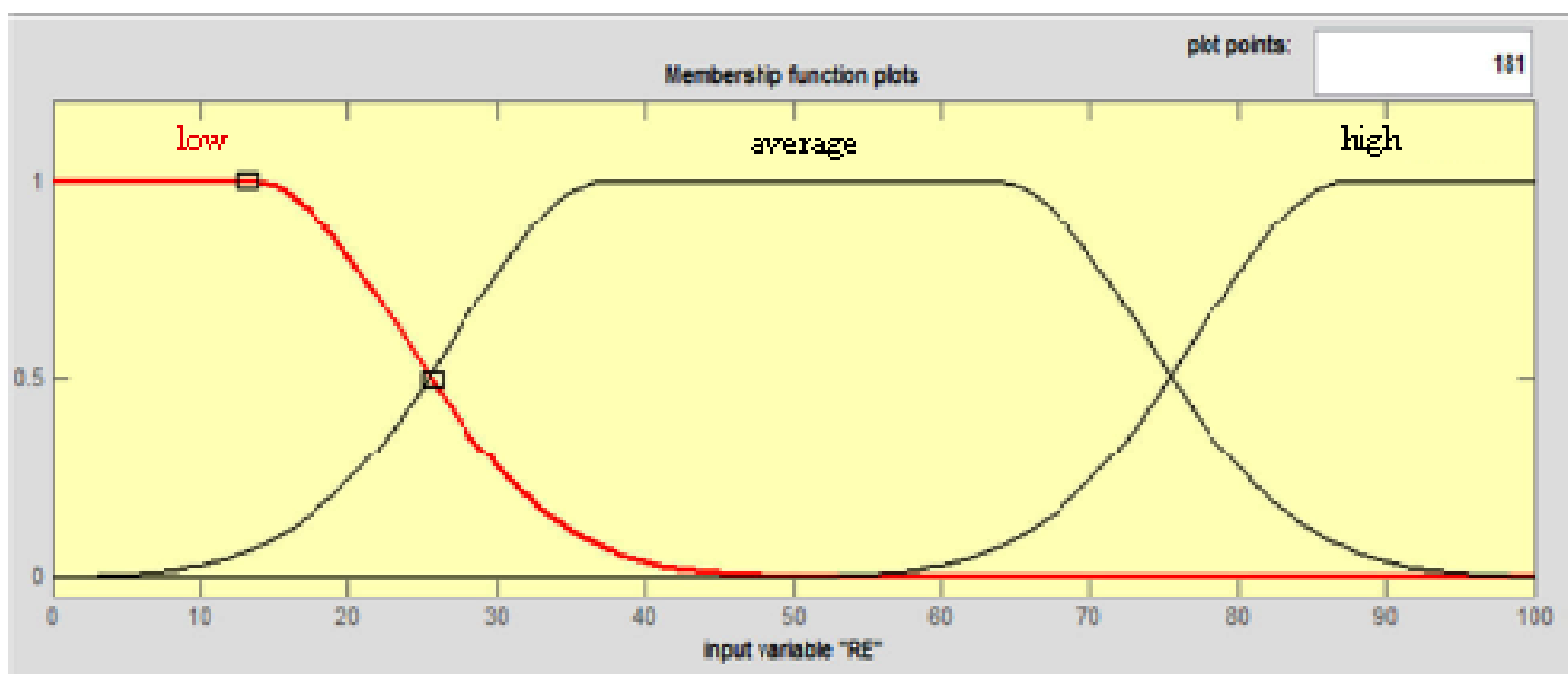

Fig. 5. Functional property for the parameter of residual energy

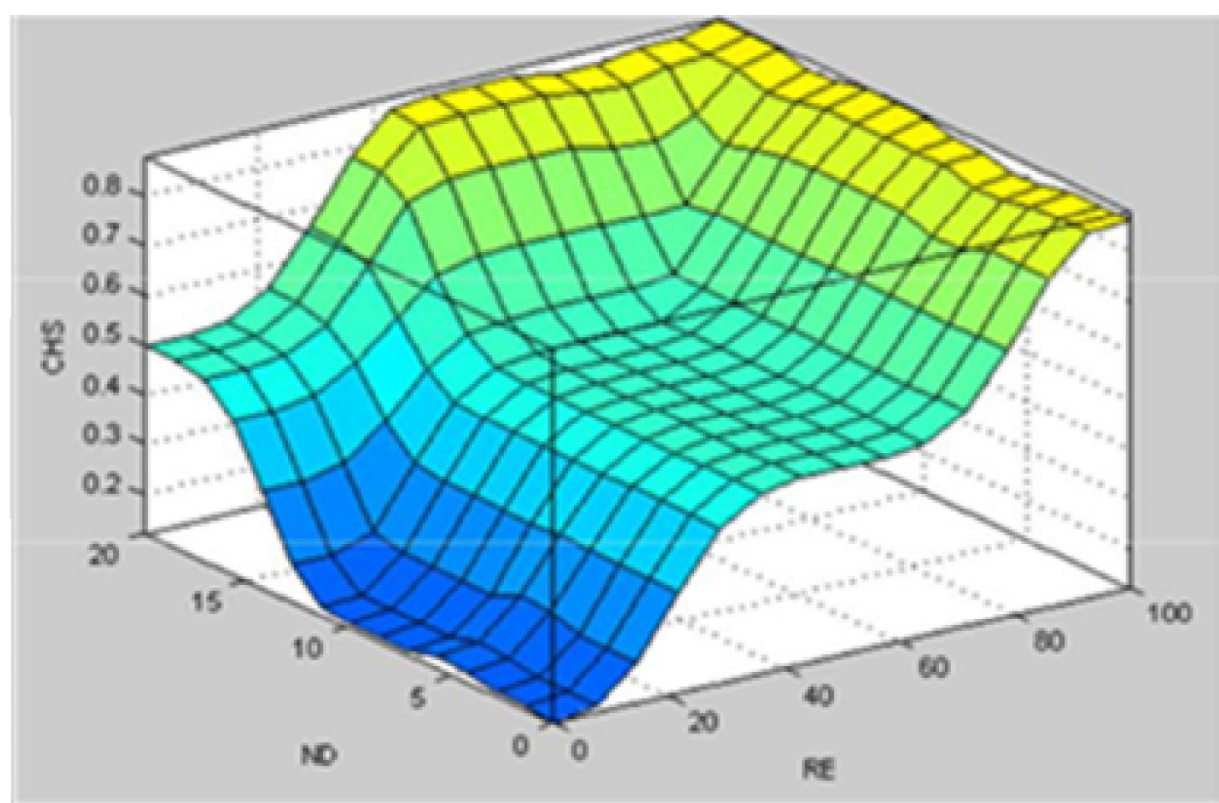

Fig. 6. Possibility of the choice of MCN on the basis of parameters of residual energy and distribution density of nodes in a cluster 


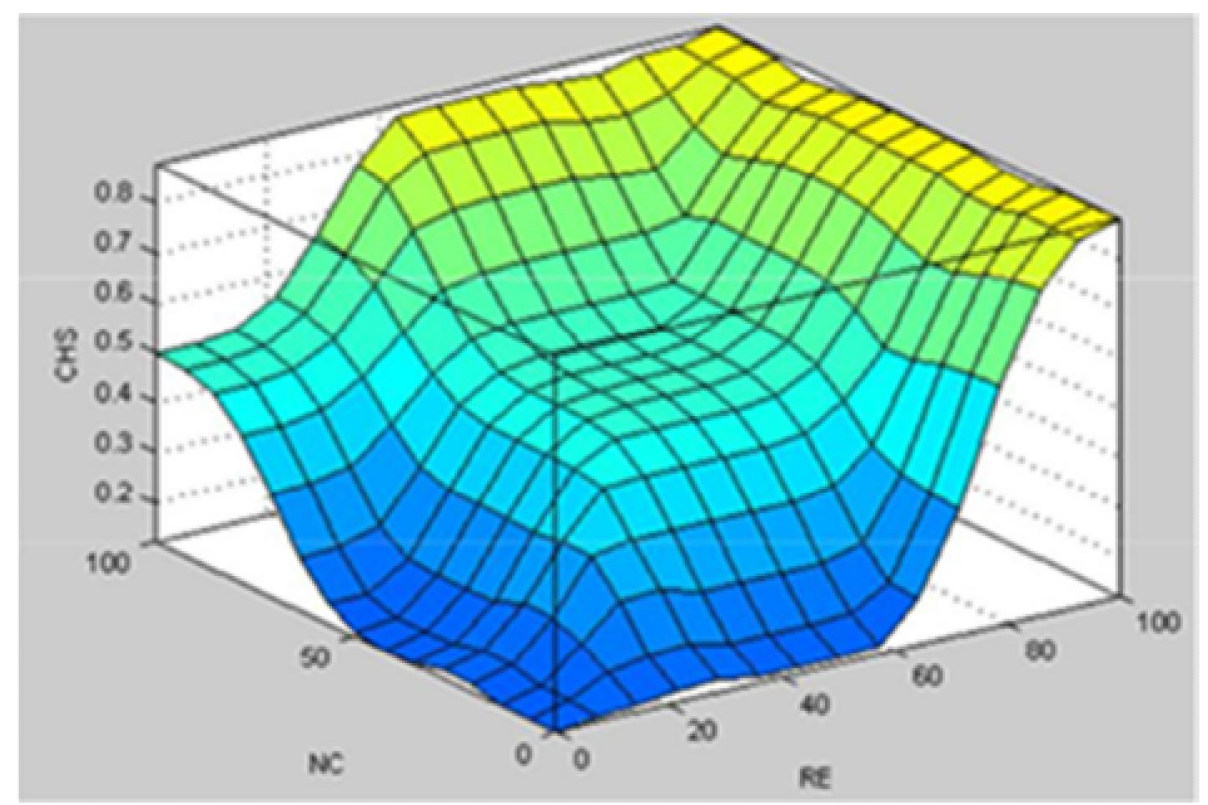

Fig. 7. Possibility of the choice of MCN on the basis of parameters of residual energy and centrality of the node

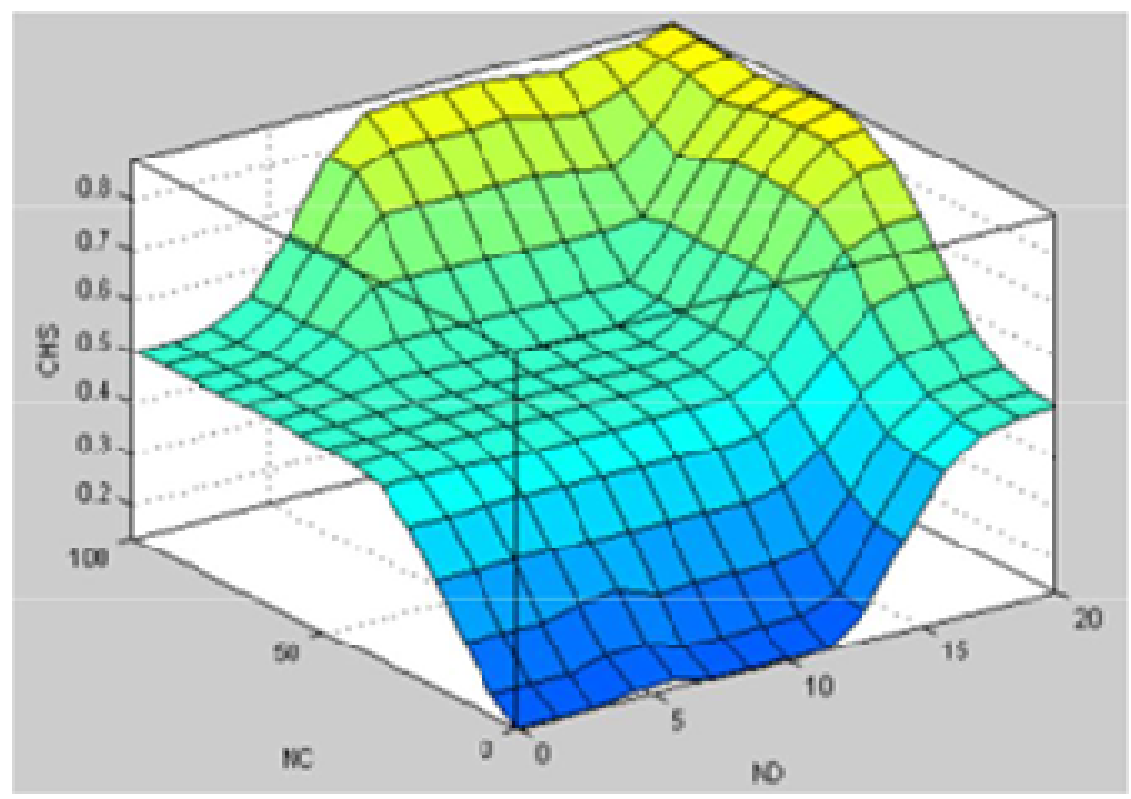

Fig. 8. Possibility of choosing the MCN on the basis of the density distribution parameters of the nodes in the cluster and the centrality of the node

\section{Conclusion}

The result of the study of a stable algorithm for the formation of the MCN of the WASN using fuzzy logic. In the proposed system, such parameters as the final energy of the WASN nodes, the distribution density of adjacent nodes in the cluster and the central node are used. The algorithm is implemented using the software package MATLAB. The simulation results show that the use of the above input parameters makes it possible to make an optimal choice of MCN, which, in turn, has a positive impact on the energy efficiency of the MCN. In the future, it is planned to investigate the 
effect of a greater number of output parameters on the choice of WASN, which determines the performance of the system as a whole.

The simulation results confirm the advantages of the proposed algorithm to use the specified input parameters to make optimal choice of the main node, which increases the energy efficiency of the wireless sensor network.

1. Callaway E. H. Wireless Sensor Networks: Archi-tectures and Protocols. CRC Press, 2004.

2. Kawadia V., Kumar P. R. // IEEE Journal on Se-lected Areas in Communications. 2005, Vol. 1. 23, p. 76.

3. Laneman J. N., Tse D. N. C., and Wornell G. W. I/ IEEE Trans. Inform. Theory. 2004, Vol. 50. No. 12. p. 3062.

4. Tu Y. S., Pottie G. J. // Proc. IEEE Vehicular Technology Conference. 2002. Vol. 1. p. 130.

5. Gerla M., Tsai T. C. // ACM Baltzer Journal of Wireless Networks. 1995. Vol. 1(3). p. 255.

6. Lin C. R., Gerla M. // IEEE Journal on Selected Areas in Communications. 1997, Vol. 15, No. 7, p. 1265.

7. Sohrabi K., Manriquez B., and Pottie G. J. // Proc. of IEEE Vehicular Technology Conference, Houston, TX, May 16-20, 1999,. p. 571.

8. Akyildiz I. F., Su W., Sankarasubramaniam Y., Cayirci E. Wireless sensor networks: a survey // Computer Networks. 2002, Vol. 38, iss. 4, p. 393-422. DOI.org/10.1016/S1389-1286(01)00302-4.

9. Akyildiz I. F., Kasimoglu I. H. Wireless sensor and actor networks: research challenges // Ad Hoc Networks. 2004, Vol. 2, iss. 4, p. 351-367. DOI.org/10.1016/j.adhoc.2004.04.003.

10. Al-Karaki J. N., Kamal A. E. Routing Techniques in Wireless Sensor Networks: A Survey // IEEE Wire-less Communication. 2004, Vol. 11, No. 6, p. 6-28.

11. Dharma P. Agrawa, Ratnabali Biswa, Aditya Gupta, Neha Jain, Anindo Mukherjee, Sandhya Sekhar. Wireless Sensor Networks (WSNs): Routing // Encyclopedia of Wireless and Mobile Communications, 2008, p. 1534-1544.

О. І. Белей

Національний університет “Львівська політехніка"

\section{ФОРМУВАННЯ ГОЛОВНОГО КЛАСТЕРНОГО ВУЗЛА В БЕЗПРОВІДНИХ СЕНСОРНИХ МЕРЕЖАХ}

(ㄷ) Белей O., 2019

У безпровідних сенсорних мережах для передачі інформації часто використовують метод кластеризації, який є одним 3 найбільш енергоефективних підходів. Оскільки головний кластерний вузол взаємодіс 3 іншими вузлами мережі, то для виконання його функцій обирається вузол з високим рівнем залишкової енергії. Запропоновано технологію вибору головного вузла на основі нечіткої логіки, що передбачає використання ряду вхідних параметрів, вплив яких продемонстровано у статті.

Ключові слова: бездротова сенсорна мережа, кластер, алгоритм, головний кластерний вузол, нечітка логіка. 